\title{
Performance Assessment of QoS Using AODV, TORA and ZRP Routing Protocol in MANET
}

\author{
Irfan Ahmad ${ }^{1,2 a}$, Fahad Masood ${ }^{1 b}$, Arbab Wajid Ullah Khan ${ }^{1 c}$ \\ RECEIVED ON 19.04.2019, ACCEPTED ON 26.07.2019
}

\begin{abstract}
In Mobile Ad hoc Networks (MANET) nodes often change their location independently where neither fixed nor centralized infrastructure is present. Nodes communicate with each other directly or via intermediate nodes. The advantages of the MANET layout lead to self-structure and compatibility to most important functions such as traffic distribution and load balancing. Whenever the host moves rapidly in the network the topology becomes updated due to which the structure of MANET varies accordingly. In the literature, different routing protocols have been studied and compared by researchers. Still, there are queries regarding the performance of these protocols under different scenarios. MANETs are not based on a predesigned structure. In this paper, the performance assessment of the Quality of Services $(\mathrm{QoS})$ for different protocols such as Ad hoc On-Demand Distance Vector (AODV), Temporally Ordered Routing Algorithm (TORA) and Zone Routing Protocol (ZRP) in the existence of the various number of communicating nodes is studied. The performance matrices throughput, end - to - end delay and packet delivery ratio are considered for simulations. Ns 2.35 simulator is used for carrying out these simulations. Results are compared for AODV, TORA, and ZRP routing protocols. The results show that AODV and TORA perform well in end - to - end delay as compared to zone routing protocol. Zone routing protocol performs well in packet delivery ratio and throughput as compared to both the other protocols.
\end{abstract}

Keywords: AODV, TORA, ZRP, MANET, Nodes

\section{INTRODUCTION}

A dhoc networks have become an attractive field for researchers in recent years. Many options look to target on combining the traffic and networks and have guaranteed to create incredible outcomes [1]. The effect of portability on networking protocols and system must be known for good design and use in a real environment. MANET is used in different areas such as commercial sectors, military battlefields, and personal area networks [2]. By introducing new technologies MANET is making an important art of next- generation networks because there is no need for infrastructure in a centralized system. In a business point of view there is less investment in mobile ad-hoc networks. MANET works on mobility with no fixed networks so multi-hop routing will be required. Different routing protocols are used because multi-hop routing for static management is very difficult. In fact, static routing cannot support portable networks [3].

This study investigates the performance assessment of routing protocols i.e. AODV, TORA, and ZRP. The performance of TORA is superior for heavy networks

${ }^{1}$ Department of Computing and Technology, Abasyn University, Peshawar, Pakistan.

Email: ${ }^{1 a}$ irfan.ahmed.mcse@gmail.com (Corresponding Author), ${ }^{1 b}$ fahad.masood@abasyn.edu.pk,

1carbabwajid2009@gmail.com

${ }^{2}$ Department of Computer Science, Khurasan University, Nangarhar, Afghanistan.

This is an open access article published by Mehran University of Engineering and Technology, Jamshoro under CC BY 4.0 International License. 
and AODV is superior for fair networks while ZRP performs well in terms of Packet delivery ratio but AODV is best in all conditions. Section II presents the literature review. Section III defines the simulations setup and the conclusion of this research is presented in section IV.

\subsection{Challenges in MANET}

Besides the attractive features of MANET, there are a few deadlocks that are briefly described below:

Dynamic topologies: Due to the mobility of nodes, the topology changes instantly and therefore dynamic nature comes into place. The network topology view changes every now and then. So for MANET, this is a problem of how to manage and control dynamic change in topology.

Routing: Since the network structure is constantly displayed proof of modification, the problem of routing packets among any combination of hubs becomes a measurement errand. Indeed most traditions should be established on responsive coordinating as opposed to table-driven.

Device discovery: Analysing the important new changes in clients and training about their existence, it requires dynamic revive to empower customized ideal route determination.

Bandwidth constrained variable capacity links: Remote associations will continue to have cut down breaking point than their designed accomplices.

Security and Reliability: Notwithstanding the customary vulnerabilities of remote affiliation, an extraordinarily selected framework has its particular security issues due to awful neighbor exchanging packets.

Scalability: Due to the portable nature of nodes, the size of specially appointed systems is changing constantly. So, adaptability is a note-worthy issue concerning security. Security instrument can also be equipped for taking care of a huge network as well as a small one.

\subsection{Classification of Routing Protocols}

The portable function of mobile nodes in MANET requires careful study. The effect of portability on networking protocols and system are known for good designs, which are used in a real environment. Those protocols which are utilized in guided media networks can be used in fixed unguided media networks with fixed access points. Division of ad hoc routing protocols are shown in Fig. 1.

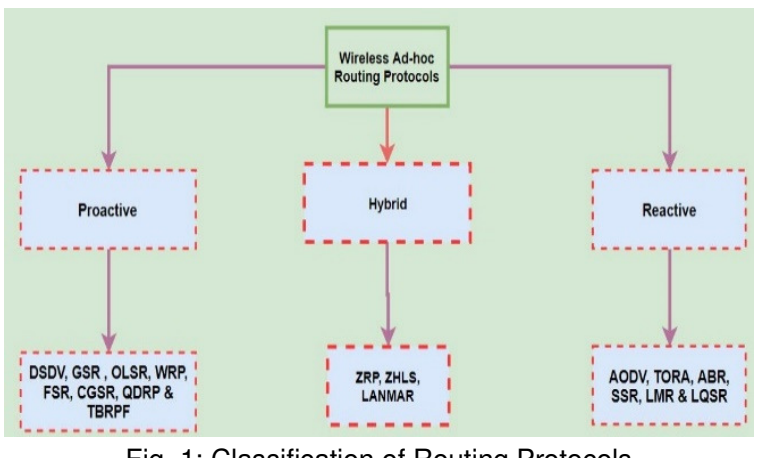

Fig. 1: Classification of Routing Protocols

\section{(a) Proactive Routing Protocol}

In a proactive routing protocol, each node is continuously looking for routes in a network. It stores all topology information if a hop wishes to transfer data to another hop, so it will take less time because all information is already available. Therefore, the latency is low in proactive routing protocol [4].

\section{(b) Reactive Routing Protocol}

In a reactive routing protocol, if node wishes to send data to other nodes in a network, routing protocol tries to establish a path for communication due to unawareness of path, the time it takes to establish a route. Therefore, the overall latency of the network goes higher [4].

AODV (Ad-hoc On-demand Distance Vector) AODV is a true reactive protocol that is more advanced than the Destination Sequence Distance Vector (DSDV) protocol because it minimizes the repetition of broadcasts process. When a hop needs to transfer a message to its receiver hop it analyses whether it has accurate path to the receiver or not If there are no routes it will start broadcasting a route request packet (RREQ) to its attached routers which again forward the demand to their neighbours and so on. At the middle hop, it accepts a legitimate path for the receiver or the receiver hop. AODV points the 
destination sequence number to assure that it has the up-to date information and overall paths are loop free. TORA (Temporary Ordered Routing Algorithm) TORA struggles to accomplish a high level of versatility by utilizing "smooth" non-hierarchical routing algorithms. TORA amasses and keeps up a Directed Acyclic Graph (DAG) set up at a target. No two nodes have a comparative highest load. Information may move out from node with higher dignity to a node with lower dignity. The key arrangement thoughts of TORA are confinement of control messages to a little game plan of a node near the occasion of a topological change [5]. To accomplish this, nodes need to keep up the routing information about bordering (one hop) node. The protocol performs three fundamental functions:

- Route Erasure

- Route Creation

- Route Maintain

At the time of path creation and maintain phases, node utilizes a dignity metric to set up a regulated Directed Acyclic Graph (DAG) settled at the receiver. From that point, links are accredited dependent on the respective dignity metric of neighboring hops. At the time of versatility, the DAG is crushed and the path support system comes into a loop to restore a DAG route at the receiver. TORA's path eradication stages essentially include flooding of a communicated clear packet through the network to delete wrong paths.

\section{(C) Hybrid Routing Protocol}

These protocols combine the best feature of table driven and On-demand routing protocols. Hence, in the last several years' number of hybrid routing protocols are suggested such as Zone Routing Protocol (ZRP), zone-based hierarchical link state routing protocol (ZHLS), Sharp Hybrid Adaptive Routing Protocol (SHARP) and Neighbour Aware Multicast Routings Protocol (NAMP), etc. [6].

\section{ZRP (Zone Routing Protocol)}

Zone Routing Protocol (ZRP) joins the benefits of the on-demand and table-driven methodologies by keeping up an updated topological design of a zone focus on every hop. Inside the zone, paths are quickly accessible. For receiver exterior the zone, ZRP utilizes a path system, whichever profit by the neighborhood routing data of the zones.

\section{RELATED WORK}

In recent years researchers proposed and developed different routing protocols for better communication. Table 1 shows a summary of all the routing protocols which are compared for different performance matrices.

The achievement of two AODV and OLSR MANET routing protocol under different scenarios using network simulator 2.33 has been investigated in [2]. They considered three performance matrices: Packet Delivery Ratio (PDR), end-to-end delay and throughput. Their outcomes point out that the figure of hops and network size has remarkable effects on the working of the routing protocol. AODV performs well as compared to OLSR in both scenarios.

AODV, Ad hoc On-Demand Distance Vector distance routing (AODVDR) and ZRP routing protocols in different network scenarios through network simulator NS-2.35 have been investigated in [7]. They used two performance metrics: packet delivery ratio (PDR) and average end-to-end delay (AE2ED). Their outcomes point out that AODVDR performs well compared to AODV and ZRP.

The performance of DSDV, AODV, Dynamic Source Routing (DSR) and Fisheye State Routing (FSR) routing protocols using the NS-2 simulator has been investigated in [8]. They used three metrics: routing overhead, throughput, and end-to-end delay. Their outcomes point out that the performance of AODV is good in terms of end - to - end delay and throughput. In packet delivery ratio the DSR is little good but overall in all categories when the network size is increasing, the AODV performs superior as compared to others.

The achievements of DSR, AODV and DSDV routing protocols using the NS-2.35 simulator has been investigated in [9]. They used four metrics: packet loss, throughput, packet delivery ratio and end-to-end delay. It is examined that performance of DSDV has been good in terms of Packet Delivery Ratio and Packet Loss. AODV was good in terms of throughput while DSR performs well in terms of end - to - end delay. Due to the significance of the packet delivery 
ratio DSDV is the superior routing protocol. DSR, DSDV \& AODV routing protocols using the NS-2.35 simulator have been investigated in [10]. They used three metrics: throughput, packet delivery ratio and end-to-end delay. Their outcomes show that the performance of AODV is superior in the high-density network compared to DSDV and DSR. In small networks where number of nodes are low, the DSR performs well as compared to AODV \& DSDV. The performance of three AODV, FSRL and ZRP MANET routing protocols in the different scenarios under a varying number of nodes using Qual Net 4.5.1 simulator has been investigated in [11]. They used three metrics: throughput, jitter, and end - to - end delay. Their overall result shows that ZRP performs well in terms of throughput as compared to FSRL and AODV, where FSRL performs well in end - to - end delay and jitter as compared to ZRP and AODV.

The working of DSR, DSDV \& AODV routing protocols using the NS-2.35 simulator has been investigated in [12]. They used four metrics: throughput, packet delivery ratio, normalized routing load, and end-to-end delay. Their outcomes point out that the performance of AODV is superior in a highdensity network as compared to DSDV and DSR. In small networks where number of machines is low, the DSR performs well as compared to AODV and DSDV.
The performance of AODV, DSDV, DSR, and TORA routing protocols at a different number of wireless connections using the NS-2 simulator has been investigated in [13]. They used four metrics: the weighted path optimality, the network's load deviation, end - to - end delay and jitter. Results show that DSDV performs well as compared to TORA in terms of weighted optimality. In terms of delay, the DSDV and AODV perform well. In load balancing the DSR performs well and in terms of jitter the DSDV is better than AODV, TORA, and DSR respectively.

Very few scientists have completed a relative work on reactive and proactive or reactive and hybrid routing protocols [6].

Table 1 shows that nobody has given the performance assessment of QoS using reactive and hybrid i.e., AODV, TORA, and ZRP.

\section{Simulations Setup}

NS-2 simulator is used by different researchers. it is advantageous to other simulators in number of ways such as computation time. It reduces the CPU utilization when other applications are executed in parallel. In this section, we have expressed the performance observation of MANET's routing protocols. The reproduction time is taken as 100 seconds. Table -2 shows the metrics and simulation environments used for experiments.

Table 1: Summary of Literature Review

\begin{tabular}{|c|l|l|l|l|}
\hline S.No. & \multicolumn{1}{|c|}{ Author Name } & \multicolumn{1}{|c|}{$\begin{array}{c}\text { Protocols } \\
\text { Compared }\end{array}$} & \multicolumn{1}{|c|}{ Performance Metrics } \\
\hline 1 & $\begin{array}{l}\text { Mohammad, A.J., Shihab, H.K., Hamad K., } \\
\text { Avon B., Salama, A.M and Aida, M. [2] }\end{array}$ & $\begin{array}{l}\text { AODV and } \\
\text { OLSR }\end{array}$ & PDR, end-to-end delay and throughput. & NS-2.33 \\
\hline 2 & $\begin{array}{l}\text { Anupam Kumar Sharma \& Munesh } \\
\text { Chandra Trivedi [7] }\end{array}$ & $\begin{array}{l}\text { AODV } \\
\text { AODVDR and } \\
\text { ZRP }\end{array}$ & PDR, AE2ED & NS-2.35 \\
\hline 3 & Yuxia Bai, Yefa Mai \& Dr. Nan Wang [8] & $\begin{array}{l}\text { DSDV, AODV, } \\
\text { DSR \& FSR }\end{array}$ & $\begin{array}{l}\text { Routing overhead, throughput, and end- } \\
\text { to-end delay }\end{array}$ & NS-2 \\
\hline 4 & $\begin{array}{l}\text { Fahad Taha AL-Dhief, Naseer Sabri, M.S. } \\
\text { Salim, S. Fouad \& S. A. Aljunid [9] }\end{array}$ & $\begin{array}{l}\text { DSR, AODV \& } \\
\text { DSDV }\end{array}$ & $\begin{array}{l}\text { Packet Loss, throughput, Packet } \\
\text { Delivery Ratio, and end-to-end delay }\end{array}$ & NS-2.35 \\
\hline 5 & $\begin{array}{l}\text { Muawia A. Elsadig \& Yahia A. Fadlalla } \\
\text { [10] }\end{array}$ & $\begin{array}{l}\text { DSR, DSDV \& } \\
\text { AODV }\end{array}$ & $\begin{array}{l}\text { throughput, Packet Delivery Ratio, and } \\
\text { end-to-end delay }\end{array}$ & NS-2.35 \\
\hline 6 & $\begin{array}{l}\text { Omar Ismael Al-Sanjary1, Ahmed Abdullah } \\
\text { Ahmed, Hewa Majeed Zangana, Musab A. } \\
\text { Aameed Aldulaimi [11] }\end{array}$ & $\begin{array}{l}\text { AODV, FSRL } \\
\text { and ZRP }\end{array}$ & $\begin{array}{l}\text { Throughput, jitter and end - to - end } \\
\text { delay. }\end{array}$ & QualNet 4.5.1 \\
\hline 7 & $\begin{array}{l}\text { Wasi Ullah, Haider Ali, A Wajid Khan, } \\
\text { Arshad Farhad, Baseer Ahmad, Adnan } \\
\text { Khan [12] }\end{array}$ & $\begin{array}{l}\text { DSR, DSDV \& } \\
\text { AODV }\end{array}$ & $\begin{array}{l}\text { throughput, Packet Delivery Ratio, } \\
\text { Normalized Routing load and end-to- } \\
\text { end delay }\end{array}$ & NS-2.35 \\
\hline 8 & $\begin{array}{l}\text { Vahid Nazari Talooki \& Koorush Ziarati } \\
\text { [14] }\end{array}$ & $\begin{array}{l}\text { AODV, DSDV, } \\
\text { DSR and TORA }\end{array}$ & $\begin{array}{l}\text { the weighted path optimality, NLD, } \\
\text { AE2ED and jitter }\end{array}$ & NS-2 \\
\hline
\end{tabular}


Table 2: Simulation Setup

\begin{tabular}{|c|c|l|}
\hline S.No & Metrics & \multicolumn{1}{|c|}{ Qualities } \\
\hline 1 & Reproduction Time & $100(\mathrm{sec})$ \\
\hline 2 & Number of Nodes & $25,50,100,200$ \\
\hline 3 & Simulation Area & $\begin{array}{l}400 \text { X 400, 800 X } \\
800,1200 \text { X 1200, }\end{array}$ \\
\hline 4 & Routing Protocol & $\begin{array}{l}\text { AODV, TORA \& } \\
\text { ZRP }\end{array}$ \\
\hline 5 & Input Rates (Pack/ Sec ) & $4,12,20,25,30$ \\
\hline 6 & Traffic Type & CBR \\
\hline 7 & Packet Size (in bytes) & 512 \\
\hline 8 & CBR Source & 12 \\
\hline 9 & Simulation Use & NS 2.35 \\
\hline
\end{tabular}

\subsection{Performance Metrics}

In this section, some of the important performance metrics are discussed.

(a) Throughput: Throughput is defined as the total number of Packets delivered over total simulation time. Mathematically,

Throughput $=\mathbf{R} / \mathbf{1 0 0}$ where $\mathrm{R}$ is the number of received bits.

(b) End-to-end delay: End-to-end delay alludes to the time taken for a packet to be transferred over a system from sender to receiver. Mathematically, End - to - end delay $=M / T$

where $\mathbf{M}$ is the total number of time taken to deliver packets for each and every target, and $\mathrm{T}$ is the number of packets received by every target hops.

(c) Packet loss: It is the number of packets missed by the router at layer 3 regard to the size of buffer outruns the time limit. Mathematically:

\section{Packet Delivery Ratio $=$ P1/P2}

where $\mathrm{P} 1$ is the number of data packets received by each target, and P2 is the total number of data packets initiated by the each sender.

\section{RESULTS AND DISCUSSIONS}

In this study, we have used the NS-2.35 network simulator with Ubuntu OS 16.04 platform. With this tool, we have carried-out the performance assessment of QoS using AODV, TORA, and ZRP routing protocols in response to various network parameters like end-to-end delay, throughput, and packet delivery ratio with various number of nodes and network sizes. From Fig. 2, it can be observed that the end - to - end delay is lower and also not good when the number of nodes gets large in AODV. TORA has larger value at the start but it decreases dramatically when the number of nodes moves from 50 to 200 hosts. ZRP has normal value at the start but it increases dramatically when the number of node moves from 50 to 100, and again decreases when the number of node moves to the higher range, it is noted that ZRP has not performed good as compared to other two protocols.

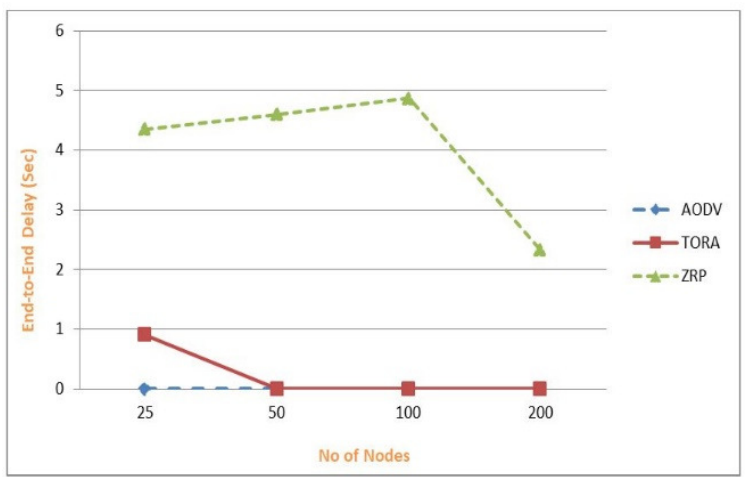

Fig. 2: End - to - End Delay vs. Number of Nodes

From Fig. 3, it is seen that the packet delivery ratio is higher but decreases dramatically when the number of nodes moves from 50 to 200 in AODV. TORA has a larger value at the start but it decreases dramatically when the number of nodes moves from 50 to 200 hosts. ZRP has larger value at the start but decreases a little when the number of node moves from 50 to 100 hosts.

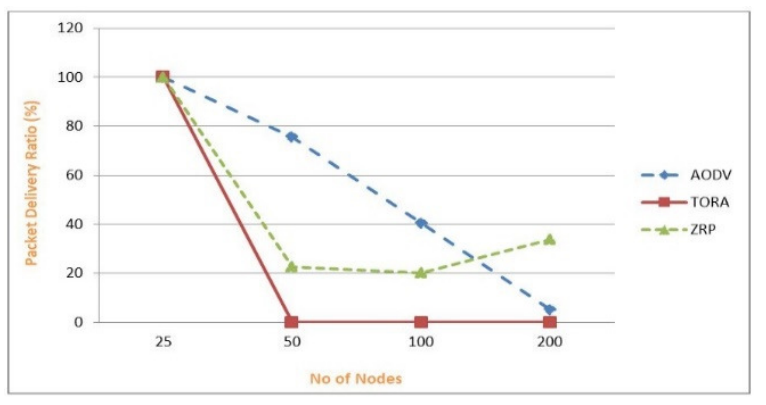

Fig. 3: Packet Delivery Ratio vs. Number of Nodes 
From Fig. 4, it is notable that the throughput starts from lower value and increases dramatically when the number of node moves from 100 to 200 hosts in AODV. TORA starts with a lower value and decreases when the number of node moves from 50 to 200 till zero but ZRP starts with lower value and moves to larger when the number of node moves from 50 to 200 hops.

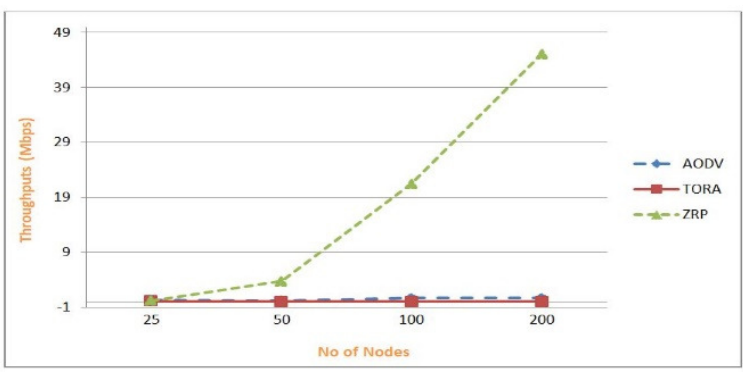

Fig. 4: Throughput vs. Number of Nodes

From Fig. 5, it is mentionable that the packet delivery ratio is started with higher value but decreases when the number of node moves from 100 to 200 hops. Throughput started with a low value and slowly increases. But the end - to - end delay is zero in all scenarios.

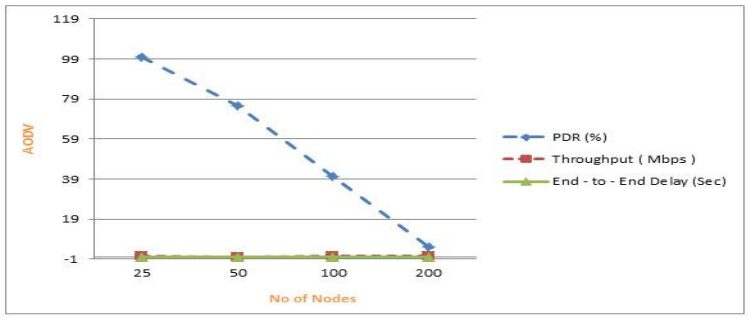

Fig. 5: AODV with all performance matrices

From Fig. 6, it is observed that all metrics started with a higher value and decreased when the number of node moved from 50 to 200 hops.

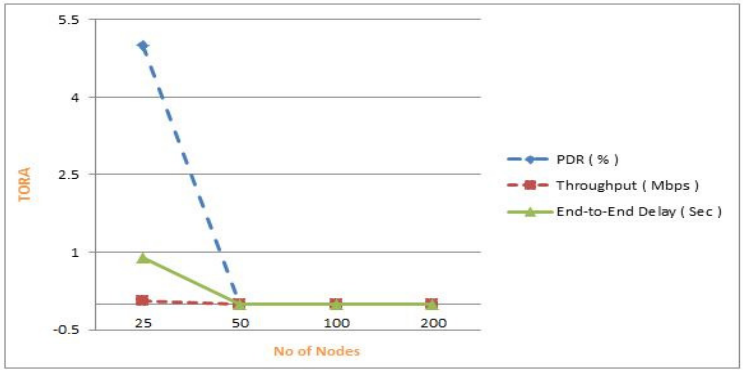

Fig. 6: TORA with all performance matrices
From Fig. 7, it is shown that the packet delivery ratio is started with larger value but decreases when the number of node moves from 50 to 200 hops.

Throughput started at zero and slowly increases. But end - to - delay is started from zero and increases when the number of node moves from 50100 and then again decreases to zero when the number of node moves from 100 to 200 hops.

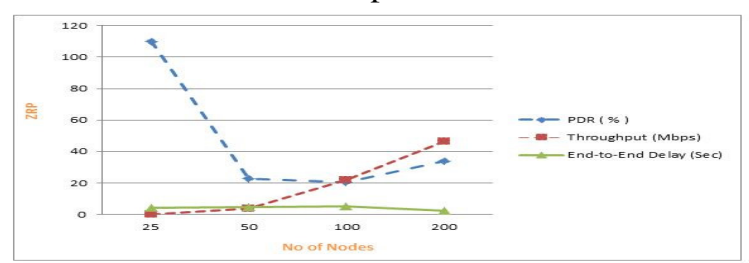

Fig. 7: ZRP with all performance matrices

\section{CONCLUSION}

Routing is an essential issue for compiling and transferring data packets accurately in the network. It is an important factor for data transportation in wireless ad hoc networks. In this paper the performance assessment of QoS using three mobile ad-hoc routing protocols, namely AODV, TORA and ZRP has been carried-out in terms of end-to-end delay, packet delivery ratio and throughput with NS 2.35 in Ubuntu 16.04 environments. Simulation results show that ZRP is better up to $30 \%$ as compared to other protocols in term of PDR and up to $90 \%$ in terms of throughput, and could be used for those networks where superior PDR and throughput are essential demand. Although AODV and TORA are better up to $70 \%$ in terms of end to - end delay and could be used in those networks where low-delay is the essential requirement.

\section{ACKNOWLEDGEMENT}

The authors thank Abasyn University Computing department for providing necessary facilities to carryout this research. The authors also thank their families and friends for their motivation and encouragement.

\section{REFERENCES}

[1] Ishtiaque M., Ahmad K.K., A Headway to QoS on Traffic Prediction over VANETs 
using RRSCM Statistical Classifier", Mehran University Research Journal of Engineering and Technology, Vol 35, No. 3, pp. 381 - 394, July, 2016.

[2] Mohammad, A.J., Shihab, H.K., Hamad K., Avon B., Salama, A.M and Aida, M., "Performance Evaluation of AODV and OLSR Routing Protocols in MANET Environment", International Journal on Advanced Science, Engineering Information Technology., Vol. 8, No. 4, pp. 1277 - 1283, 2018.

[3] Bouhorma, M., Bentaouit, H. and Boudhir, A. (2009) 'Performance Comparison of Adhoc Routing Protocols AODV and DSR', IEEE, International Conference on Multimedia Computing and Systems, October 2009, pp. 511-514.

[4] Pandey, K., and Swaroop, A., "A Comprehensive Performance Analysis of Proactive, Reactive and Hybrid MANETs Routing Protocols", International Journal of Computer Science, Vol. 8, No. 6, pp. 432 441., November 2011.

[5] Gupta A.K., Sadawari H., Verma A.K., "Perforance Analysis of AODV, DSR and TORA Routing Protocols", IACSIT International Journal of Engineering and Technology, Vol.2, No.2, pp. 226-331, 2010.

[6] Ramasuramanian V., Hass Z.J., Sirer E.G., "SHARP: A Hybrid Adaptive Routing Protocol for Mobile Ad hoc Networks", Proceedings of the $4^{\text {th }}$ ACM International Symposium on Mobile Adhoc Networking and Computing, Annapolis, Maryland, USA, pp. 303-314, June 1-3, 2003.

[7] Sharma A.K., Trivedi M.C., "AODVDR Routing Protocols in MANET", Proceedings of the Second International Conference on Computational Intelligence and Communication Technology, Ghaziabad, India, pp. 231-236, February 2016.

[8] Bai Y., Mai Y., Wang N., "Performance Comparison and Evaluation of the Proactive and Reactive Routing Protocols for MANETS", Proceedings of the Wireless Telecommunication System (WTS), Chicago, IL, USA, pp. 26-28, April 2017.
[9]

Al-Dhief F.T., Sabri N., Salim M.S., Fouad
S., Aljunid S.A., "MANET Routing Protocols Evaluation: AODV, DSR and DSDV Perspective", Proceedings of the Malaysian Technical Universities Conference on Engineering and Technology, Malaysia, 2017.

[10] Elsadig M.A., Fadlalla Y.A., "Mobile Ad hoc Network Routing Protocols: Performance Evaluation and Assessment", International Journal of Computing and Digital Systems, Vol. 7, No.1, January 2018.

[11] Omar A.I., Ahmed A.A., Hewa M.Z., Musab A.M., Ali Muhammad H.A., Saeed H.A., "An Investigation of the Characterisitics and Performance of Hybrid Routing Protocol in MANET, International Journal of Engineering and Technology, Vol. 7, pp. 4954, 2018.

[12] Wasi Ullah A.H., Khan A.W., Farhad A., Ahmad B., Khan A., "Performance Assessment of Reactive Routing Protocols in Moble Ad hoc Networks Under CBR Traffic Using NS2", Proceedings of the International Conference on Wireless Communications, Signal Processing and Networking (WiSPNET), Chennai, India, pp. 23-25 March 2016.

[13] Talooki V.N., Ziarati K., "Performance Comparison of Routing Protocols for Mobile Ad hoc Networks", Proceedings of the Asia Pacific Conference on Communications, Busan, South Korea, 31 $1^{\text {st }}$ August $-1^{\text {st }}$ September, 2006. 